\title{
LA ACTUALIDAD DEL PENSAMIENTO DE JAN PATOČKA: \\ UNA INVITACIÓN A PENSAR EL VÍNCULO ENTRE VULNERABILIDAD Y SOLIDARIDAD POLÍTICA ${ }^{1}$
}

\author{
Emre Şan \\ 29 Mayis University, Estambul, Turquía
}

\begin{abstract}
Resumen: La vida política de un disidente se vincula al combate y a la lucha. Sin embargo, estas nociones no son suficientes para expresar el sentimiento de sufrimiento e indignación (thymos) involucrados en el disenso. La resistencia de los disidentes presupone un cierto tipo de vulnerabilidad creada por la inseguridad existencial bajo regímenes autoritarios. Tiene sentido sólo como una forma de no-sometimiento al poder, como una actividad. ¿Cuáles serán entonces las consecuencias políticas de la vulnerabilidad pensada como condición de posibilidad de la resistencia política? Si la vulnerabilidad es parte del significado y de la acción de la resistencia, ¿cómo podemos reinterpretar la dimensión política de la disidencia hoy en día? La relación entre vulnerabilidad y resistencia se interpreta a menudo en términos de oposición porque, a diferencia de la resistencia colectiva, la vulnerabilidad parece requerir una cierta forma de protección y se define por la pasividad. Siguiendo el análisis de la teoría de la solidaridad de los conmovidos de Patočka, que describe la resistencia ante un estado de guerra permanente en forma de movilización total deshumanizadora, pretendo mostrar el papel del reconocimiento de la vulnerabilidad en las prácticas de resistencia política y desobediencia civil.
\end{abstract}

\section{Descriptores: Disidente $\cdot$ Solidaridad $\cdot$ Polemos $\cdot$ Vulnerabilidad $\cdot$ Desobediencia civil}

Abstract: The political life of a dissident refers to combat and struggle but these notions are not enough to express the feeling of suffering and indignation (thymos) involved in dissent. The resistance of dissidents presupposes a certain type of vulnerability created by existential insecurity under authoritarian regimes. It has meaning only as a non-submission to power, as an activity. So what will be the political consequences if we think of vulnerability as the condition of possibility of political resistance? If vulnerability is part of the meaning and action of resistance how can we then reinterpret the political dimension of dissent today? The relationship between vulnerability and resistance is often interpreted in terms of opposition because, unlike collective resistance, vulnerability seems to require a certain form of protection and is defined by passivity. Following Patočka's analysis of theory of the solidarity of the shaken which describes a resistance to a permanent state of war in the form of dehumanizing total mobilization, I aim to show the role of the recognition of vulnerability in the practices of political resistance and civil disobedience.

Keywords: Dissident $\cdot$ Solidarity $\cdot$ Polemos $\cdot$ Vulnerability $\cdot$ Civil $\cdot$ Disobedience

\footnotetext{
${ }^{1}$ Este artículo ha sido traducido a partir de la versión francesa y modificada de una conferencia pronunciada en inglés en Estambul en mayo de 2018 en el departamento de filosofía de Koç Üniversitesi. El titulo original de esta conferencia es: "Political dissidence and solidarity: thinking today with Jan Patočka." Las citas han sido traducidas por Mariana Larison salvo las de Patočka para las cuales se encontraba ya una traducción publicada.
} 
Hoy en día, la disidencia política no ha perdido su razón de ser y sigue caracterizando la situación de los disidentes en todo el mundo. Los disidentes reaparecen en países donde la democracia no ha podido triunfar o donde reinan falsas democracias, en dictaduras modernas y en zonas de conflicto. Como escribe Michel Eltchaninoff en su libro Les Nouveaux dissidents, "el disidente no es un oponente extranjero, un disruptor externo. Lo que lo hace temible es que proviene del mismo sistema que critica. Es su producto típico, a veces, incluso, un producto modelo. Lo que hace que su protesta sea más eficaz y audible para todos" (Eltchaninoff, 2016, p. 18).

La vida política de un disidente está relacionada al combate y a la lucha, pero estas nociones no son suficientes para expresar el sentimiento de sufrimiento e indignación (thymos) involucrados en la disidencia. La resistencia de los disidentes implica un cierto tipo de vulnerabilidad, creada por la inseguridad existencial experimentada bajo regímenes autoritarios. Sólo tiene sentido como un nosometimiento al poder, como una actividad, y sólo puede liberarse del poder en, y a través de, la experiencia de una reconducción a su falta de sentido. ¿Cuáles serán entonces las consecuencias políticas de una vulnerabilidad considerada como condición de posibilidad de la resistencia política? Si la vulnerabilidad es parte del sentido y de la acción de la resistencia, ¿cómo puede reinterpretarse hoy la dimensión política de la disidencia?

El pensamiento de Jan Patočka, heredero de la tradición fenomenológica de Edmund Husserl y de la analítica existencial de Martin Heidegger, nos invita a pensar este vínculo entre vulnerabilidad y resistencia. Hablar de filosofía política en Patočka no es algo evidente, pues no tratamos aquí con un filósofo que analice conceptualmente temas como el funcionamiento democrático, la justicia social o la teoría del Estado. Su originalidad reside, en cambio, en analizar, desde un punto de vista fenomenológico, conceptos como los de acción colectiva, guerra, historia, campo político y polemos. Pero creemos que es precisamente así como el filósofo checo ofrece uno de los análisis más profundos sobre los vínculos fundamentales de la libertad, sobre su posibilidad y su debilitamiento. En el marco de estos análisis toma forma el concepto "herético" de polemos, basado en una teoría de la "solidaridad de los conmovidos" que enfatiza la formación de una nueva comunidad, una comunidad por venir. Tomando como hilo conductor estos estudios sobre la "solidaridad de los conmovidos", que describen la resistencia al estado de guerra permanente, indagaremos cuál es el rol que juega el reconocimiento de la vulnerabilidad en las prácticas de resistencia política. Intentaremos mostrar así que la solidaridad de los conmovidos puede pensarse como la acción de una comunidad de sujetos vulnerables contra la persecución, y que el nacimiento de la política puede leerse como una experiencia de libertad. 


\section{LA EXPERIENCIA DEL FRENTE}

En su gran texto titulado "Las guerras del siglo XX y el siglo XX como guerra" (Patočka, 2016, pp. 171-193), Patočka intenta comprender el aspecto auténtico de la experiencia del frente. Según él, la Primera Guerra Mundial es el acontecimiento decisivo en la historia del siglo XX, y debe pensarse a partir de su experiencia más devastadora.

La idea común y general que se encontraba en el trasfondo de esta guerra era la convicción -lentamente gestada desde tiempo atrás- de que no existe nada parecido a un sentido objetivo del mundo, $y$ de que es asunto de fuerza y poder realizar tal sentido dentro de lo que está al alcance del hombre. (Patočka, 2016, p. 173)

Según Patočka, la experiencia del frente revela el sentido predeterminado del mundo moderno así como su movilización total y deshumanizadora. Bajo la forma de una movilización total, la guerra expresa la esencia metafísica de la modernidad tecnológica como voluntad de poder. Sin embargo, la plena movilización de la Primera Guerra Mundial no se detuvo en 1918, sino que, por el contrario, se perpetuó bajo otras formas. Lo que viene después de la guerra no es ni paz ni guerra, es una guerra contra la guerra. La guerra continúa durante la paz y continúa moldeando la existencia social del hombre. Como escribe Marc Crépon "el mundo sigue siendo el mismo y nuestra existencia está sujeta a los mismos imperativos que lo que llevaron a la guerra: lo que Patočka llama las fuerzas del día" (Crépon, 2007, p. 396). La Guerra Fría es un ejemplo característico de este tipo de enfrentamiento más o menos violento entre dos entidades, Estados Unidos y la Unión Soviética, que se presentan cada una como depositaria de los valores de la humanidad y como sus defensores por la fuerza. Patočka analiza esta situación a partir de la oposición entre, por un lado, lo que él llama "las fuerzas del día", la vida y la paz, y, por otro, la noche, la muerte y la guerra. Paradójicamente, desde su perspectiva las fuerzas del día, la vida y la paz son las responsables de los conflictos destructivos del siglo XX, pues, para el filósofo checo, las "fuerzas del día" designan todo aparato de supra-civilización y pretenden manipular los entes para controlarlos. ¿Qué hay detrás de esta paradoja? ¿Cómo podemos entenderlo?

Pues bien, en el fondo, no es sólo la esperanza de una verdadera paz lo que se ve amenazado por esta movilización total, sino ante todo la posibilidad misma de una relación responsable con la verdad, de una "vida en la verdad" tal como fue inaugurada con el nacimiento de la filosofía en la Grecia antigua. Se trata de una vida éticamente comprometida en, y a través de, la vida de los otros a partir de la afirmación de su supervivencia. La historia de la humanidad es así la historia de la relación del hombre con la verdad, la historia de su clarividencia o de su ceguera. La 
verdad no es una simple cuestión teórica que se resuelve con métodos objetivos: "Es la lucha interior del hombre por su libertad esencial, es la cuestión de la autenticidad del hombre" (Patočka, 1990, p. 37). Sólo se puede captar en la acción, y sólo un ser que realmente actúa puede relacionarse con la verdad. Mientras no sea así, el hombre permanece ajeno a sí mismo, es decir, en una experiencia de sufrimiento, ansiedad y desgarramiento. Desde este punto de vista, el siglo XX caracteriza, para Patočka, la imposibilidad de la posibilidad de un sentido auténtico de la vida. Incluso los regímenes totalitarios, que trabajan para difundir un sentido hegemónico a través de la movilización y la propaganda, no pueden evitar la contaminación del nihilismo. Pero, a pesar de todo, una comunidad no puede vivir en la certeza de la falta de sentido.

Para responder a esta paradoja y encontrar una falla o excepción en la hegemonía de las "fuerzas del día", Patočka describe la experiencia vivida por los soldados durante la Primera Guerra Mundial en el frente como "la experiencia de la noche". El frente se revela así como un espacio del fin del espacio, el lugar del fin del hogar sin ser todavía el hogar de un otro. Esta experiencia del frente, en la medida en que es una experiencia negativa, es la experiencia de la noche. Así, en palabras del autor, "Al irrumpir la noche sobre nosotros como una posibilidad insuperable, quedan descartadas las posibilidades pretendidamente supraindividuales del día y este sacrificio se proclama la auténtica supraindividualidad" (Patočka, 2016, p. 185) El punto a tener en cuenta es éste: la comunidad que se funda en el sacrificio no es una comunidad de individuos armónicos, sino la comunidad de los "conmovidos" que, desde ese momento, rechazan la moralidad que conforma el pensamiento "de la vida y de la muerte". Como escribe Marc Crépon,

Se trata, pues, de dos sentidos de sacrificio que se contraponen y, con ellos, de dos modos de relación con la muerte, cuya incompatibilidad radical debe ser exhibida. El primero es un pensamiento de "vida y muerte" que se distingue, como hemos visto, en todos los niveles, por su poder de alienación y de continuidad [...] El segundo consiste en volver contra las "fuerzas del día" el sacrificio impuesto a millones y millones de hombres en todos los frentes. Al poder de alienación (que procede de su instrumentalización) se opone su poder de liberación y sacudida (Crépon, 2007, p. 404).

Esta forma de sacrificio no debe ser entendida por sus efectos y no puede ser justificada por sus resultados. Se basa en el conocimiento de la vulnerabilidad humana y en la necesidad de protegerla. Comprender la vulnerabilidad humana hace posible sacrificar y comunicar el significado de ese sacrificio a los demás. Para el combatiente que se enfrenta al peligro abriéndose a la posibilidad de dar su propia vida, estrictamente insustituible, la guerra ya no se vive simplemente desde fuera como una experiencia de sufrimiento y negación. Se vive internamente 
como una afirmación, una prueba del movimiento mismo de la vida. El dolor no se olvida, no se suprime, sino que se interpreta ahora como aquello que intensifica la relación consigo mismo. Como escribe Patočka, "el dolor, agarrado y sostenido en su amplitud, nos enseña a descubrir el mundo y nos muestra que somos libres de interpretar su sentido" (Patočka, 1990, p. 39).

En este sentido, según Patočka, el shock que produce el frente no es un trauma momentáneo, sino un cambio fundamental en la existencia humana que se produce a través del "sentimiento de plenitud de sentido" (Patočka, 2016, p. 179). Este sentimiento se estructura en dos momentos. Por un lado, el frente es la experiencia del sin sentido y del absurdo del mundo. Para Patočka, esta ausencia de sentido es el origen del sentido, porque sólo a través de la experiencia de una ausencia total de sentido se hace posible la cuestión misma del sentido. ${ }^{2}$ Por otro lado, esta visión del fin revela una preocupación por la libertad. Como escribe Nicolás de Warren, "esta libertad es a la vez transformadora y reveladora, pero ella implica también una sacudida del sí mismo tal como lo define el mundo natural de significados predeterminados" (Warren, 2014, p. 237). Entrar en el frente requiere, en efecto la suspensión y neutralización de las convenciones y normas sociales.

\section{Polemos y el CAMPo POLÍtico}

Con todo, la experiencia del frente sigue siendo una experiencia exclusivamente individual. Cada uno se ve proyectado solo hacia una libertad de la que toma conciencia, pero que no puede transformar en un acontecimiento colectivo. El frente no tuvo consecuencias estrictamente colectivas. La única manera de superar esta soledad aparece entonces con la "solidaridad de los conmovidos":

"El enemigo es copartícipe en esta misma situación, es codescubridor de la libertad absoluta. Es aquél con quien es posible la concordia en la discordia. Es copartícipe de la conmoción del día, de la paz y de la vida sin esta cima. [...]: es el ámbito de la solidaridad de los conmovidos a pesar de sus discordias y conflictos" (Patočka, 2016, p. 185)

\footnotetext{
${ }^{2}$ Como lo escribe Patočka de manera precisa y sintética: "Pasar por la experiencia de la pérdida de sentido significa que el sentido al que quizá volvamos no será ya para nosotros puramente un hecho dado directamente y sin quebrantar. Más bien, será un sentido reflexionado, que buscará razones y responderá de sí mismo. Experimentar esta pérdida significa que, como consecuencia que, como consecuencia, el sentido no estará nunca ni dado ni ganado para siempre. Significa que surgirá una nueva relación, una nueva forma de remitirse a lo que tiene sentido. En efecto, el sentido sólo se podrá descubrir en una actividad derivada de una insuficiencia de sentido que está en búsqueda; sólo se podrá descubrir como punto de fuga de la problematicidad, como epifanía indirecta. Si no andamos errados, este hallar el sentido en una búsqueda que emana de la no presencia del mismo, como un nuevo proyecto de vida, constituye el sentido de la existencia de Sócrates.”(Patočka, 2016, pp. 99-100).
} 
¿Cómo podemos pensar un camino alternativo al antagonismo entendido como una guerra que opone a los hombres? En este sentido, Patočka nos ofrece una reflexión arqueológica de la comunidad de los conmovidos a partir de una relectura de la visión heraclítea del ser como polemos. Esto permitiría indicar un camino similar, en parte divergente pero quizás complementario, del enfoque fenomenológico al mismo tiempo que mantener una dinámica de la argumentación sobre la teoría de la solidaridad de los conmovidos.

Según Heráclito, el polemos se encuentra en el origen del mundo y de los hombres, es el padre de todas las cosas y la ley divina de la que se nutren todas las leyes humanas. La guerra no es, en principio, la lucha armada entre hombres, sino una lucha cósmica. El mundo mismo es polémico y este combate es visible en todas las formas de unidad, desde la familia hasta la sociedad civil, y se manifiesta en los acontecimientos sociales e históricos. Debemos entender, con Heráclito, que la oposición es el fundamento de las relaciones humanas, aunque la mayor parte del tiempo se vuelva injusta y alienante. En este sentido, polemos no sólo refiere a la discordia, sino también a la unidad producida por esta discordia. Al igual que el frente en la guerra, el espacio de la polis revela la desigualdad de las relaciones sociales y pone de relieve una cierta esfera de conflicto. Como lo señala Patočka, esta unidad polémica es el punto común entre el alma y la polis. En efecto, la polis puede describirse como el alma en la medida en que es el lugar mismo del conflicto entre pasión y razón, entre deseos y logos. De este modo, el verdadero sentido del conflicto, que puede surgir en el frente en circunstancias excepcionales, es la realidad de la política. En política, el hombre experimenta una "vida libre como tal" (Patočka, 2016, p. 75), es decir, expuesta al peligro. Como en la guerra, hay una experiencia límite, una metabolê que conmociona la existencia. El hombre se encuentra ante un mundo que se le abre por primera vez. La vida vivida en el modo de la aceptación es conmovida de arriba a abajo. Patočka va aún más lejos: “en esta renovación del sentido de la vida, que trae consigo el surgimiento de la vida política, está al mismo tiempo contenido el germen de la vida filosófica." (Patočka, 2016, p.77). Esta observación es decisiva, ya que revela la originalidad de su enfoque. Polemos es la unidad y el origen común de la ciudad y la filosofía como "cuidado del alma" (epimeleia tes psukhes) en sus dimensiones política y ética. El hombre es responsable del sentido que lo compromete con el cuidado del alma, pero no sólo de su propia alma, sino del alma en general: es responsable de la justicia en la comunidad. Para decirlo brevemente, el cuidado del alma no es una idea romántica y no puede apoyarse en un ego. No se puede pensar el cuidado del alma aislado de la sociedad, sus conflictos internos y su estructura problemática. En sus seminarios titulados Platón y Europa, Patočka define el "cuidado del alma" de tres maneras: "primero, como un proyecto general sobre el ente; segundo, como proyecto para 
una nueva vida en el seno del Estado; y, tercero, como una elucidación de lo que es el alma en cuanto tal." (Patočka, 1997, p. 96). Nos enfrentamos aquí a las tres preguntas fundamentales de la filosofía para Kant: ¿Qué podemos saber? ¿Qué debemos hacer? ¿Qué podemos esperar? Es decir: ontología, política y ética.

Por lo tanto, debemos ampliar nuestra interpretación de la solidaridad de los conmovidos y de la experiencia del frente de guerra y llevarla al campo político y ético de la polis. A la figura del soldado le sigue así la del ciudadano:

El espíritu de la polis es el espíritu de la unidad en la discordia, en la lucha. No es posible ser ciudadano (politês) de otro modo que en la comunidad de unos con otros. Esta misma discordia es la que crea la tensión, el tono de la vida de la comunidad. Ella crea la forma de este espacio de libertad que los ciudadanos se ofrecen y se rehúsan mutuamente; y ofrecen dicho espacio de tal manera que, para su acción, buscan apoyo y vencen las resistencias. (Patočka, 2016, pp. 78-79)

En otras palabras, la discordia y la lucha pueden dar lugar a un poder dentro de la comunidad mayor que el de sus partes constituyentes. Es un poder que sabe y ve. En otras palabras, es la phronêsis: "Ver el mundo y la vida en totalidad significa ver a pólemos, eris, como lo común: xunon esti pasi to phronein (pensar es común a todos)" (Patočka, 2016, p. 79). La phronêsis de los ciudadanos es ante todo una lucha, una acción y un debate que procura convencer a los otros del interés general, el de la ciudad toda. La polis no puede surgir del altruismo o de una coalición de intereses porque ella es una unidad en la discordia, es la unificación de vidas conmocionadas para proteger la libertad de los ciudadanos. Los adversarios se reencuentran en "la conmoción del sentido dado" y forman así un nuevo modo de comunidad. La polis es, pues, el espacio político de la solidaridad de los conmovidos. El conflicto es a la vez fuente de voluntad colectiva y de leyes, pues la justicia y la injusticia sólo pueden fundarse en el conflicto de ideas. La unidad de una comunidad libre se sostiene en la lucha contra la hegemonía de las ideologías y lo hace de tal manera que una unidad polémica no pueda terminarse en una paz ilusoria en la que una parte impondría sus condiciones a la otra. Sólo es posible gracias a la participación en el campo político de los ciudadanos a través de la acción y el discurso. El conflicto de ideas es convocado de igual manera por todas las partes de la comunidad.

El fundamento del campo político como "la conmoción del sentido dado" refiere a la lucha incesante de los sujetos políticos por la libertad. Como escribe Patočka, "Comprender que aqui está el lugar donde se desarrolla el verdadero drama de la libertad; comprender que la libertad no es algo que sólo vaya a llegar «después» -cuando la lucha haya acabado- , sino que, antes bien, el drama de la libertad tiene su lugar propio precisamente en esta lucha" (Patočka, 2016, p. 189). Esta línea de pensamiento nos obliga a convocar la tesis de Patočka sobre la 
dimensión metafísica de la libertad. En un ensayo inacabado llamado "El platonismo negativo", Patočka propone una interpretación de la libertad humana a través de la lectura fenomenológica del chôrismos platónico:

El misterio del chôrismos es idéntico a la experiencia de la libertad: la experiencia de un distanciamiento respecto de las cosas reales, la experiencia de un sentido independiente del objetivo y de lo sensible, que se obtiene invirtiendo la orientación primitiva y "natural" de la vida (Patočka, 1990, p. 87).

Por paradójico que parezca a primera vista, hay que admitir que la experiencia que surge de la conmoción del sentido dado no se relaciona con nada, no conoce nada, no descansa en nada, no recibe nada, es decir, aquello con lo que se relaciona no es nada de ente: esta experiencia original es la de la libertad. La libertad es, pues, una experiencia en la que no se da nada, no se descubre nada. $\mathrm{O}$, más precisamente, nada de ente, una nada de ente que corresponde al todo del ente, a la totalidad. Es un vivir en el que nada se vive; la dimensión en la que el sujeto se compromete con nada, en el sentido trascendental de un poder arrancarse de todo, es decir, de un poder comprometerse con la nada. En este sentido, el sujeto emerge según Patočka de una puesta en juego de sí mismo: en el riesgo, el "yo" emerge como singular. Esta experiencia nunca es adquirida de manera definitiva, es la negación de cualquier contenido y es en esta negación, precisamente, donde el sujeto surge:

La libertad no deja de ser por ello asunto de la experiencia. La libertad es una experiencia del riesgo que puede ser afrontado o esquivado. Esta experiencia no es pasiva, no se impone como ocurre con todo lo proveniente de los sentidos [...] la experiencia de la libertad es la experiencia de: una conquista, no de su posesión tranquila (Patočka, 2007, p. 83) ${ }^{3}$.

En otras palabras, la libertad es la experiencia de una posibilidad que nos es única. Se confunde con la acción, por así decirlo, y por eso suele pasar desapercibida. En ella ya no encuentro más un objeto, sino que estoy expuesto a mí mismo y por eso mismo es experiencia de un riesgo. Tal riesgo no se refiere tanto a una categoría de la acción como a una dimensión de la acción, pues una acción que estuviera enteramente sujeta a la influencia de lo dado no sería propiamente una acción. Por el contrario, la acción verdadera implica siempre una dimensión de vacío. Lanzarse al vacío es, por lo tanto, una de las dimensiones constitutivas de cualquier acción.

En lo que sigue utilizaremos esta reflexión para describir, desde un punto de vista fenomenológico, la vida política de la comunidad de los conmovidos.

\footnotetext{
${ }^{3}$ Traducción modificada por Iván Ortega relativamente a la traducción inicial.
} 


\section{VIDA POLÍTICA Y SOLIDARIDAD}

La vida política se encuentra en una búsqueda constante de su propio fundamento, que no es una vida segura sino la libertad. Para desplegar esta idea, estudiaremos primero la relación entre solidaridad y vida política. La vida política no sólo se caracteriza por el antagonismo, sino también por la solidaridad (Patočka, 2016, p. 207). Abre al hombre a su posibilidad fundamental entendida como una vida en la amplitud. En un texto de 1939 titulado "Equilibrio y amplitud en la vida", Patočka habla de la vida en la amplitud:

La vida en la amplitud tiene el sentido de una puesta a prueba de sí mismo y de una protesta. En la amplitud, el hombre se expone a la posibilidad extrema (que para la vida corriente son posibilidades abstractas y alejadas) y protesta contra aquéllas que se presentan como corrientes y evidentes. (Patočka, 2007, p. 42).

Según Patočka, quien asume esta posibilidad es libre en el sentido más profundo de la palabra. Al aceptar el peligro, la libertad conquista la seguridad completa, asegura al hombre una vida vivida desde su ser más propio o fundamento. La libertad hace que el hombre se comprometa en un combate consigo mismo por el cual se convierte en dueño de su propio ser, de lo más profundo que habita en él, de la profundidad más extrema que puede alcanzar.

La vida política es una existencia disidente. La política no es sólo la protectora del orden social dado y la realizadora de una promesa para el futuro. Se refiere a la forma en que se establece el vínculo social así como a las profundas grietas de la sociedad. Según Patočka, el campo político debe ser descrito a partir de la aparición de otros individuos y comunidades, y de nuestra aparición ante nosotros mismos en la relación con ellos. Por lo tanto, se refiere a las relaciones intersubjetivas y a las instituciones que las estructuran. Siguiendo la descripción de la crisis de la humanidad europea y la filosofía de Husserl así como la analítica existencial de Heidegger, el filósofo checo interpreta la idea de comunidad a través de la idea del Lebenswelt como mundo de nuestra vida, lejos de la idea de un mundo entendido como mera unidad substancial. El Lebenswelt es el centro de la acción humana en su ser y se da a partir del cuidado de los otros con los que el sujeto coexiste. Patočka retoma así la idea husserliana de un "mundo de vida" y la interpreta como un suelo originario de la experiencia política. Esto es obviamente esencial porque, según Patočka, la acción política, en sentido fenomenológico, corresponde a la relación especial que se establece con el proceso de aparición del mundo y de los otros. La crisis descrita por Husserl no nos lleva al apocalipsis, sino a la erosión de las instituciones políticas y al estrechamiento del campo político. En este sentido, la fenomenología política no es una teoría normativa y no intenta 
resolver las crisis. Lo que busca, en cambio, es pensar más allá de las instituciones políticas en crisis. Al guardar una distancia crítica, revela cómo funciona la crisis y problematiza sus propios supuestos en vistas a un rediseño del campo político. Pero para darse cuenta de esta preocupación, es necesario primero diagnosticar el conflicto que determina una sociedad y la tensión activa en la comunidad política. Así, los temas fenomenológicos reciben una perspectiva completamente diferente cuando son restituidos en el contexto de un debate político. Se entiende entonces que el origen de la política como mundo de la vida requiera la acción de una epojé política tanto como el campo que ésta abre. En efecto, la epojé abre el camino a la problematización de todos los mecanismos preestablecidos de las instituciones políticas. Como escribe Mathieu Cochereau, “es política porque neutraliza todo lo que 'ata y compromete', es decir, todas las ideologías" (Cochereau, 2015). Sin embargo, cuando se piensa en la polis como la institución por excelencia de la voluntad burocrática, la importancia política de la epojé crea una tensión entre las instituciones y el pensamiento políticos. En tanto que acción política, la epojé deja en suspenso la legitimidad y la estructura del sentido histórico de estas instituciones. Cabe señalar aquí que Patočka reconoce esta tensión y, en lugar de reducirla, la coloca en el centro de su pensamiento.

A la luz de estas consideraciones preliminares, que pretenden abrir el campo de una fenomenología política, es posible hacer algunas observaciones. Un fenómeno de estas características surge hoy bajo la forma de la reducción de la vida política a la gestión económica. El problema es en efecto que la política se ha transformado por el conocimiento objetivo de la economía. La gobernanza política contemporánea se ha reducido a la administración de la economía según recetas neoliberales. Hoy en día, los modelos financieros que dependen de expectativas racionales y cálculos objetivos se presentan como ciencias exactas. Este fue el diagnóstico ya anunciado por Husserl en su trabajo sobre la crisis de las ciencias europeas. A pesar de las enormes desigualdades, la política habla con precisión matemática sobre el crecimiento y la prosperidad de los "seres económicos". Más aun, como lo escribe Thierry Pouch, "la economía, encerrada en su sistema matemático, se ha desvinculado de la idea de que el conocimiento del mundo es inseparable del conocimiento del hombre mismo" (Pouch, 2010, p. 194). Del mismo modo que la naturalización de la razón, la economía se naturaliza, la racionalidad de la física matemática se aplica a los comportamientos humanos.

Como resultado, la ilusión de la armonía, las fórmulas económicas y las desigualdades gigantescas ocupan el lugar del polemos y se sustituyen al debate democrático y a la idea de igualdad. El sistema representativo pierde su respetabilidad porque las instituciones políticas se convierten en mecanismos que buscan justificar decisiones contrarias al interés público. El problema es que la definición de interés 
público queda reducida a un pueblo aritmético que tiene el poder de la última palabra en las elecciones. Del mismo modo, en lugar de funcionar como representación democrática, la opinión pública parece haberse exiliado al campo de las encuestas, una suerte de pueblo ficticio que ocupa el lugar de un pueblo real imposible de ser figurado. De esta manera, la escena política se convierte en un ámbito de certezas objetivas y la justicia social se reduce a la visión del mundo específica de una parte de la sociedad. Esta situación reproduce las crisis en lugar de prevenirlas, y allana el camino para un estado de excepción permanente. Esto no carece de consecuencias respecto del problema de la acción política, ya que dicha gestión de la crisis restringe el ámbito de esta acción y del pensamiento crítico. El campo político pierde su autonomía, se vuelve más permeable a los golpes de actores externos. Sin embargo, la originalidad de la acción política radica en su capacidad de distanciarse de la realidad calculable y observable y de llevar la dimensión ética del hombre al campo político al "conmocionar el sentido dado".

Cabe señalar que, para describir la vida política de los conmovidos, es necesario analizar una vez más la idea de solidaridad en su contexto político. El concepto de solidaridad se refiere a la responsabilidad mutua que se establece entre los miembros de un grupo social sobre una base sólida y firme. Ser solidario con los demás requiere formar parte de un todo en el que las diferencias entre los miembros se vuelven invisibles. La solidaridad tiene que ver tradicionalmente con la solidez, consiste en formar una unión con los demás sobre la base firme y estable de una identidad compartida. Sin embargo, como muestra Gustav Stranberg, es precisamente este solidus o suelo compartido el que, para Patočka, se conmueve (Stranberg, 2015, p. 101). Aquellos que participan en una "solidaridad de los conmovidos" no encuentran un suelo firme. Es una solidaridad generada por la agitación existencial y la desorientación. En otras palabras, los miembros de esta comunidad no comparten nada porque la experiencia de ser conmovidos es aquello que los une. De hecho, el único aspecto unificador de esta solidaridad se encuentra en la conmoción del sentido dado, en el abismo del sentido en cuanto tal. Los conmovidos se encuentran en la ausencia de una pérdida común y en la pérdida común de los fundamentos. Es, por tanto, una solidaridad más allá de la solidez. Es una experiencia de confrontación con la finitud y el sinsentido, la extrañeza y la angustia (Angst) en los términos de Heidegger. Sin embargo, según Heidegger, la angustia no es una experiencia colectiva. Pues el "distanciamiento, el estar-enel-uno, [la] igualación" (Heidegger, 1986, p. 170) inherente al ser-con implica que el Dasein se encuentra en la "publicidad", bajo el control de otros, es decir, no en sí mismo. Las posibilidades en este tipo de vida cotidiana no pertenecen a nadie. Mientras que la angustia es nuestra primera experiencia de libertad, ella coloca "al Dasein delante de su ser libre para... (propensio in) la propiedad de su ser como 
una posibilidad siempre ahí" (Heidegger, 1986, p. 237). Al igual que la epojé de Husserl, que nos permite pasar de una actitud natural a una filosófica, la angustia de Heidegger reenvía al Dasein que se encuentran en la publicidad diaria del "uno" hacia la posibilidad que es su posibilidad más propia.

Sin embargo, para Patočka, cuando se trata de la solidaridad de los conmovidos, la experiencia de la angustia es una experiencia colectiva e histórica. Aunque el filósofo checo conserva la estructura formal de la experiencia de la angustia, no se limita exclusivamente a la dimensión individual del fenómeno, porque la conmoción del sentido dado afecta a toda la comunidad. Según él, el surgimiento de la vida política de la polis griega, entendida como una entrada en la historicidad y la problematicidad del sentido, resulta de una conmoción de este tipo en el orden mítico. Como escribe Etienne Tassin, "polis es el nombre dado al espacio dedicado al cuestionamiento colectivo del sentido" (Tassin, 2009, p. 329). La "conmoción del sentido" significa aquí el cuestionamiento y la pérdida del sentido aceptado, admitido, dado, establecido. Lleva a la comunidad política a construir constantemente su propio sentido. La solidaridad es, por tanto, una experiencia auténtica del ser-con que se realiza en la vida política.

\section{VULNERABILIDAD Y RESISTENCIA}

A partir de lo visto hasta aquí, podemos comprender que la cuestión en juego en el debate sobre la solidaridad de los conmovidos no es sólo teórica, sino también política y social. La solidaridad de los conmovidos es una comunidad de vulnerabilidad respecto del otro absolutamente necesaria y primordial, y sólo como tal puede ser una comunidad libre e histórica. La vulnerabilidad debe ser considerada como una condición humana fundamental que requiere al mismo tiempo una respuesta ética y una acción política. De este modo, ella se vuelve el lugar de una experiencia política auténtica que reclama principios éticos $\mathrm{y}$, en este sentido, tal camino de pensamiento debe construirse a partir de una confrontación con los acontecimientos, de una investigación relacionada con su esclarecimiento y con la determinación de las condiciones para la acción política.

Las preguntas que podemos hacernos ahora son las siguientes: ¿puede la solidaridad de los conmovidos servir de punto de partida teórico para profundizar la investigación filosófica contemporánea sobre los movimientos de desobediencia civil? Si la vulnerabilidad es parte del significado y de la acción de la resistencia, ¿cómo puede reinterpretarse la dimensión política de la disidencia? Para responder a estas preguntas, necesitamos un enfoque fenomenológico de los movimientos sociales y de la desobediencia civil como práctica política de los disidentes. Esto nos permitirá conceptualizar la acción colectiva de los nuevos disidentes y la solidaridad a partir de la relación entre vulnerabilidad y resistencia. En esta línea, 
el sentido de la vida política del que habla Patočka respecto de la resistencia contra la movilización total deshumanizadora de la guerra puede ayudarnos a releer el compromiso de la insubordinación, así como el poder de protesta y resistencia de los movimientos sociales. Este acercamiento nos invita también a reflexionar sobre la relación entre la actitud disidente, cuyo fundamento se presenta como ético, y la solidaridad de los conmovidos como modelo de compromiso político. Los dos ejes de interpretación están vinculados por la cuestión de la vulnerabilidad y su importancia política eminente.

La guerra no es el único medio en el que el peligro es tal que muchas personas acaban expuestas a la experiencia de la conmoción. Podemos pensar en la reaparición de este fenómeno en levantamientos contemporáneos como los de la Plaza Tahrir en El Cairo, Taksim en Estambul, Maidan en Kiev, Puerta del Sol en Madrid, Syntagma en Atenas, donde las barricadas, con su fuerza simbólica y figurativa, se convierten en las nuevas líneas de frente. Los movimientos sociales en forma de concentraciones y ocupaciones de plazas, protestas contra los poderes dominantes, las insurrecciones civiles, son todas movilizaciones que llaman a la disidencia del orden establecido y del poder dominante. Los levantamientos contemporáneos han demostrado, a pesar de sus diferencias culturales, ideológicas e históricas, cómo una comunidad de sujetos vulnerables se convirtió en política al tomar posesión de su propio espacio y tiempo, al crear un "otro mundo común". Cada levantamiento es una iniciación inesperada al dolor, al sufrimiento y a la descomposición, así como a la solidaridad de los conmovidos. Estos levantamientos plantean simultáneamente demandas de democracia y contribuyen a renovar el significado social y político del espacio público a través de una asociación voluntaria.

La dimensión simbólica y el funcionamiento práctico (bloqueo u ocupación) de la desobediencia es la solución que se requiere cuando hay vulnerabilidad colectiva y necesidad de solidaridad política. Es un intento de dar un medio de expresión a los que no lo tienen, porque hoy la cuestión de la vida política de un disidente es una cuestión de expresión. En su aspecto fenomenológico, la cuestión política se convierte en el problema de la expresión y de la aparición en el espacio político. Tal espacio no es sólo un espacio de representación, sino también un tipo de espacio fenomenal. Se trata de la aparición de una práctica democrática de autodeterminación colectiva para combatir la erosión de las instituciones y el estrechamiento del campo político.

Como la definición de "vida en la amplitud” (Patočka, 2007, 42) de Patočka, la desobediencia civil tiene el sentido de una prueba y de una protesta, y es en el marco de esta multivocidad que su sentido puede ser entendido. De este modo, no se trata sólo de una multitud que manifiesta en la calle o de un grupo que interviene para romper el orden de las cosas. Es una dificultad que causa sufrimiento y una 
reivindicación de justicia como forma de resistencia. Permite poner de relieve los principios éticos que motivan a quienes desobedecen la ley, no para sí mismos, sino para defender una causa que es superior a sus propios intereses. Porque como escribe Patočka sobre la Carta 77: "hay una autoridad superior, que obliga tanto a los individuos en su conciencia moral como a los Estados en virtud de la firma con la que validan importantes convenciones internacionales" (Patočka, 2009, p. 166). Como la disidencia, la desobediencia civil es una herramienta de lucha democrática que permite conciliar las exigencias éticas con la radicalidad de la acción. Consiste, pues, en abrir el terreno político sobre el que debe expresarse la acción colectiva en un intento por cambiar las leyes injustas y por oponerse a una política gubernamental que viola los derechos humanos fundamentales. Por lo tanto, se trata de una elección tanto ética como política.

En su libro Philosophy and Resistance in the Crisis, Costas Douzinas analiza la relación entre la prueba y la protesta:

La desobediencia niega, la resistencia crea. La importancia de la desobediencia radica precisamente en iniciar el proceso de producción de nuevas subjetividades. Eleva a las personas a ciudadanos que se legislan por sí mismos en vez de recibir órdenes y mandos (Douzinas, 2013, p. 98). ${ }^{4}$

Es sorprendente constatar que, como en el caso de la solidaridad de los conmovidos, estas nuevas subjetividades aparecen primero bajo la forma de la vulnerabilidad física. La solidaridad de los conmovidos es originalmente una solidaridad corporal. En la línea del frente, experimento a través de mi cuerpo la epojé o reducción de mi relación primordial con el mundo. ${ }^{5}$ Del mismo modo, la corporalidad colectiva de la desobediencia forma un cuerpo político (body politics) que neutraliza las convenciones y normas sociales. La liberación del ethos social consiste en hacer aparecer el espacio público de la acción corporal colectiva. Así, la desobediencia civil se convierte en un juicio político que se incorpora, ante todo, al sentimiento de sufrimiento e indignación, en lugar de vincularse a la reflexión abstracta. A este respecto, Judith Butler nos llama la atención sobre el siguiente hecho:

Un levantamiento no surge de mi indignación ni de la tuya. Los que se levantan lo hacen juntos, reconociendo que sufren de una manera en la que nadie debería hacerlo. Por lo tanto, un levantamiento requiere el reconocimiento no sólo de que lo que el individuo sufre es compartido, sino de que un grupo está viviendo más

\footnotetext{
4 "Disobedience negates, resistance creates. The importance of disobedience lies precisely in starting the process of production of new subjectivities. It raises people from takers of orders and commands into self-legislating citizens" (Douzinas, 2013, p. 98); traducción propia.

${ }^{5}$ Sobre este punto, que no podemos desarrollar aquí, nos referimos al artículo de Meacham (2012), pp. 239-251, así como al artículo de Cochereau (2016), pp. 46-69.
} 
allá de un sentido compartido de sus propios límites. Los individuos y los grupos padecen el sometimiento y, por lo tanto, al levantarse, quien lo hace es este cuerpo con otros cuerpos, a partir de una negativa compartida de vivir más allá del límite de lo que puede o debe ser soportado (Butler, 2016, p. 24). ${ }^{6}$

Los cuerpos de los ciudadanos constituyen el lugar de la desobediencia frente a ciertas normas predeterminadas de la sociedad. Se unifican con el espacio de protesta y transforman su sentido cultural e histórico. Porque la desobediencia difumina los límites entre la acción y el comportamiento, entre lo social y lo político. La vulnerabilidad de los espacios de protesta sólo puede pensarse sobre la base de la vulnerabilidad física. La vulnerabilidad humana, por ejemplo la de las cadenas humanas en las protestas, responde a la violencia con la fuerza simbólica de la solidaridad. Porque cuando se pisotea la dignidad, no se trata más de una cuestión de libertad. Los ciudadanos en la protesta arriesgan sus vidas para afirmar su dignidad y su voluntad de vivir libremente.

Además de una vulnerabilidad de los ciudadanos proporcional a la violencia del poder, existen vulnerabilidades diferenciales entre los componentes internos de la desobediencia civil. Porque la desobediencia civil es una acción pública que puede reunir a ciudadanos que no comparten necesariamente las mismas convicciones. La participación del adversario político en la misma situación en la que podemos llegar a un acuerdo en la diferencia o a una unidad en la discordia (polemos) es aquello que abre un espacio público de iguales en el que se logra la libertad. Como la solidaridad de los conmovidos, la desobediencia civil implica encuentros políticos inesperados que no pueden ser definidos por una yuxtaposición de identidades ideológicas, sociales o étnicas. Por el contrario, los que participan en la desobediencia civil ganan su identidad de "disidentes" a través de sus acciones mutuas y solidarias. Las acciones políticas que construyen nuevos modos del compartir y del producir revelan de esta manera las vulnerabilidades invisibles de la sociedad. Así es como la solidaridad forma relaciones sociales que desafían la estructura jerárquica de la sociedad construida por el clima antagónico de la política. El espacio político antagónico puede describirse como aquel en el que ciertos grupos de la sociedad son los actores predominantes y algunos son relegados al lugar de los sujetos vulnerables. La violencia del antagonismo consiste, por tanto, en debilitar la capacidad del hombre para actuar en el espacio público.

El miedo como modo de gobierno, como instrumento de atomización de la sociedad, que permite su esclavitud espiritual, política y moral, es un modo de

\footnotetext{
6 "An uprising does not well up from my indignation or from yours. Those who rise up do so together, recognizing that they suffer in ways that no one should. So an uprising requires a recognition not only that what the individual suffers is shared, but that a group is living beyond a shared sense of its limit. Individuals and groups both undergo subjugation and so in rising up, it is this body with other bodies, and from a shared refusal to live beyond the limit of what can be, or should be, endured" (Butler, 2016, p. 24); traducción propia.
} 
garantizar obediencia y de criminalizar la acción colectiva. Un régimen de este tipo es el punto de encuentro entre el desencanto político y la confusión social relacionada con la incapacidad de resolver la cuestión de la igualdad. En este contexto, el espacio de convivencia de las diferentes vulnerabilidades de la resistencia, un espacio abierto por la solidaridad de los conmovidos, permite a los ciudadanos experimentar la "publicidad" de una manera impredecible. Los actores de la desobediencia civil se dan cuenta de sus propias posibilidades de acción a través de otros "extranjeros" políticamente vulnerables. En este sentido, un espacio público de estas características tiene el potencial de proporcionar una base más sólida para la unidad política que las comunidades basadas en "coaliciones de interés". Sin embargo, esta relación ética no puede explicarse invocando una ley moral o un comportamiento altruista. Las nuevas subjetividades conmovidas no aparecen gracias a roles preestablecidos en la sociedad, sino precisamente por su respuesta a la interpelación ética de un acontecimiento. Como Simon Critchley escribe en su libro Infinitely Demanding Ethics of Commitment Politics of Resistance:

El sujeto se compromete éticamente en términos de una exigencia recibida de esa situación, por ejemplo una situación de injusticia política: una huelga, un acto de brutalidad policial, un error judicial o lo que sea. Pero la demanda no es reductible a esa situación. Es, más bien, una demanda situada que se dirige, en principio, a todos y es por lo tanto universal (Critchley, 2007, p. 42). ${ }^{7}$

La relación ética sólo es posible a través de una reivindicación de igualdad que va más allá de la situación particular de cada uno, y es por esto que la vulnerabilidad puede ser una fuerza movilizadora para la resistencia política. No se trata sólo de la igualdad en sentido económico, sino de la igualdad en el sentido de una sociedad en la que realmente hay una producción de lo común. La acción colectiva da a todos la libertad de hacer oír su voz sin establecer ninguna jerarquía entre ellos. La voz de la desobediencia es, por lo tanto, indisolublemente personal y colectiva, y cuanto más expresa lo singular, más puede representar lo colectivo. Porque las luchas sociales y políticas tienen como objetivo transformar el modo en que funciona la política haciendo aparecer las vulnerabilidades invisibles y las capacidades de acción de los sujetos sin voz.

\footnotetext{
7 "The subject commits itself ethically in terms of a demand that is received from that situation, for example a situation of political injustice: a strike, an act of police brutality, a miscarriage of justice or whatever. But this demand is not reducible to the situation. It is, rather, a situated demand that is addressed, in principle, to everyone and hence universal" (Critchley, 2007, p. 42); traducción propia.
} 
Butler, Judith (2016). “Uprising”. En Catalogue de l'exposition Soulèvements. DidiHuberman, Georges (ed.). Paris: Gallimard, pp. 23-37.

Cochereau, Mathieu (2015). "Politique de l'épochè”. Implications Philosophique. (http:// www.implications-philosophiques.org/actualite/une/politiques-de-lepoche/). Publicado el 7 de julio de 2015.

Cochereau, Mathieu (2016). "Polemos ou le sens du conflit: guerre et politique chez Jan Patočka”. Cahiers d'études lévinassiennes 14, pp. 46-69.

Crépon, Marc (2007). "La guerre continue : Note sur le sens du monde et la pensée de la mort”. Studia Phoenomenologica VII, pp. 395-409.

Critchley, Simon (2007). Infinitely Demanding: Ethics of Commitment, Politics of Resistance. London and New York: Verso.

Douzinas, Costas (2013). Philosophy and Resistance in the Crisis: Greece and the Future of Europe. Cambridge: Polity Press.

Eltchaninoff, Michel (2016). Les Nouveaux dissidents. Paris: Stock,

Husserl, Edmund (1976). La Crise des sciences européennes et la phénoménologie transcendantale. Granel, Gérard (trad. fr.). Paris: Gallimard.

Heidegger, Martin (1986). Être et Temps. Vezin, François (trad. fr.). Paris: Gallimard.

Meacham, Darian (2012). “L'Europe, L'histoire et la vie: quelques réflexions sur la philosophie de l'histoire de Jan Patočka". En Jan Patočka, Liberté, existence et monde commun. Frogneux, Nathalie (ed.), pp. 239-251. Paris: Editions du Cercle Herméneutique.

Patočka, Jan (1988). Le monde naturel et le mouvement de l'existence humaine. Abrams, Erica (trad. fr.). Dordrecht/Boston/London: Kluwer Academic Publishers.

Patočka, Jan (1990). Liberté et sacrifice. Écrits politiques. Abrams, Erica (trad. fr.). Grenoble: Million.

Patočka, Jan (1997). Platon et l'Europe. Séminaire privé du semestre d'été 1973. Abrams, Erica (trad. fr.). Lagrasse: Éditions Verdier.

Patočka, Jan (2009). “Ce que la Charte 77 est et ce qu'elle n'est pas”. Esprit 352, pp. 166-169.

Patočka, Jan (2007). Libertad y Sacrificio. Ortega, Iván (trad. esp.). Salamanca: Ediciones Sígueme.

Patočka, Jan (2016). Ensayos heréticos sobre filosofía de la historia. Ortega, Iván (trad. esp.). Madrid: Encuentro.

Pouch, Thierry (2010). “La science économique sous le regard de Husserl”. L'Homme et la société 175/1, pp. 165-196.

Strandberg, Gustav (2015). “The Solidarity of the Shaken”. Baltic Worlds 1/2, pp. 101-102.

Tassin, Étienne (2009). "Pensée hérétique et politique dissidente". Tumultes 32-33/1, pp. 329-350.

de Warren, Nicolas (2014). "Homecoming Jan Patočka's reflections on the first world war". En Phenomenologies of Violence. Staudigl, Michael (ed.), pp. 207-247. Leiden: Brill. 